\title{
A situação florestal do Rio Grande do Sul
}

\section{Histórico}

O Rio Grande do Sul, dentro da Federação, é conhecido como um estado agropastoril por excelência, com uma fisionomia de grandes áreas de cultivos e campos de criação.

Em passado incerto, anterior à ocupação portuguesa e espanhola, a situação era certamente bem diferente. Dados desencontrados, sem razoável comprovação, avaliam a cobertura florestal original em aproximadamente $40 \%$ (Bettiol \& Maslak, 1973) no Século XIX, em relação à área total do Estado.

Para uma avaliação retroativa da vegetação original, somente contamos com as evidências dos restos sobreviventes desta vegetação e teorias que combinam estes restos a dados climáticos e edáficos atuais. Os dados históricos existentes são muito recentes, como os de Lindman (1906) e St. Hilaire (1821)

Rambo (1957) discute e admite o avanço das matas subtropicais sobre o campo e a mata com araucária.

Shultz (1957) considera que os campos do Rio Grande do Sul são resultantes de interferência humana, e que a existência dos campos do norte e centro do Estado é devida às queimadas em épocas pré e pós-colombiana, completadas pela devastação florestal dos últimos cem anos. Admite, também, que parte dos campos do sul (pampa) são originais (comunidade clímax).

Atualmente, qualquer área de terras abandonadas no Sul sempre tende a uma vegetação de maior porte, tendo como resultante um clímax florestal. Excetuam-se, no caso, áreas do pampa e outras pequenas áreas em que problemas edáficos não o permitem.

Aplicando o método dos diagramas de Walter, em dados climáticos do Estado, onde se combinam números de precipitação e evaporação, o resultado é sempre um saldo positivo de água no ambiente, o que também é um bom indício de clima propício a florestas. Os pequenos testemunhos de matas ainda existentes, ilhadas nos campos e lavouras, bem como a existência de "matas de galeria" em praticamente toda a extensão estadual, também apontam esta tendência florestal.

Pode-se, então, concluir que o Estado do Rio Grande do Sul tem uma acentuada tendência florestal, e que originalmente era predominantemente coberto por florestas, com uma área minoritária de campos. Com base em estudos mais aprofundados, de clima, solo e palinologia, poderemos avaliar estas proporções numericamente.

\section{Situação atual das florestas nativas}

As estimativas de cobertura florestal atual são bastante discrepantes, como de 1,8\% (Bettiol \& Maslak, 1973), reduzidas para 1,5\% por Ferreira (1983) e outros números diferentes periodicamente citados.

Sabemos que dados recentes obtidos por satélites, ainda não-publicados, avaliam esta cobertura em aproximadamente $6 \%$ da superfície do Estado.

Os restos ainda existentes pertencem a diver- 
sas formações florestais como segue: mata tropical pluvial perenifólia da Costa Atlântica; mata subtropical com araucária; meda tropical pluvial perenifólia dk Alto Uruguai; matas mistas da Depressão Central e Serra do Sudeste.

As classificações fitogeográficas (ou propostas) existentes, Hueck (1972), Rambo (1956), Superintendência de Desenvolvimento da Região Sul Sudesul (1978) e Shultz (1957), não são completas, e insatisfatórias principalmente quando tratam das matas situadas ao sul da borda do planalto. Há uma certa concordância quanto às formações do Alto Uruguai, da mata com araucária e mata atlântica. Uma classificação correta, no momento, é muito difícil pela falta de maiores dados sobre a composição local das matas, bem como pela falta de informações sobre eventuais associações e distribuição global das espécies.

Rambo (1957) avaliava o número de espécies florestais (arbóreas, arbustivas e herbáceas) em oitocentas e segundo Schultz (1957), o número de espécies arbóreas e subarbóreas nativas no Estado é de cerca de 375.

A mata da Costa Atlântica é de porte alto, com árvores de 25 a 35 metros de altura, e é caracterizada pela presença de elementos tropicais oriundos do norte do Brasil, como o palmito (Euterpe edulis), baguaçu (Talauma ovata) e bicuíba (Virola oleifera). Em nossa região se resume a restos localizados em Torres e adjacências, nas planícies e encosta da Serra Geral. Provavelmente, não existem mais áreas intactas.

Sobre o planalto basáltico, temos matas perenifólias em que a fisionomia da formação é conferida pelo pinheiro-brasileiro (Araucaria angustifolia), emergente sobre o dossel da mata contínua e atingindo até 35 metros de altura. A mata também é caracterizada pela presença de grande número de canelas (família Lauraceae), casca-de-anta (Drymis brasiliensis), e pinheiro-bravo (Podocarpus lambertii). Existem, atualmente, três amostras razoáveis desta mata no Parque Nacional dos Aparados da Serra (10.250 hectares), na Reserva Riológica de AracuriEsmeralda (272 hectares) e no Parque Florestal Estadual do Espigão Alto (1.432 hectares).

A floresta do Alto Uruguai, marginal ao Rio Uruguai e afluentes, tem sua origem ao norte, na bacia do Rio Paraná e seu limite austral, no Brasil, na Região das Missões no Rio Grande do Sul. É uma mata de grande porte, com árvores de mais de 35 metros de altura, caracterizada pela presença da grápia (Apuleia leiocarpa), canafístula (Peltophorum dubium), timbó (Ateleia glazioviana) e alecrim (Holocacalyx balansae). Desta formação ainda existem boas amostras no Parque Estadual Florestal do Turvo
(17.491 hectares) e no Parque Estadual Florestal de Nonoai (17.498 hectares); o primeiro, porém, ameaçado pela construção de uma futura hidroelétrica.

$\mathrm{O}$ que denominamos de matas mistas da Depressão Central e Serra do Sudeste é, em realidade, um conjunto de comunidades florestais ainda não perfeitamente sistematizadas. Nas encostas da Serra Geral e em parte do Vale do Jacuí, em sentido lesteoeste, encontra-se uma mata formada por espécies migradas da Costa Atlântica (oeste) e Alto Uruguai (noroeste). Assim, encontramos lá, por exemplo, a grápia (Apuleia leiocarpa) procedente do noroeste, e o palmito (Euterpe edulis) procedente do Leste. Também espécies do Sul ali são encontradas.

A mata predominante na Depressão Central, sobre solo granítico, é relativamente baixa, com altura máxima de cerca de 12 metros. Sua composição se deve, principalmente, a espécies das famílias Myrtaceae (cambuins, guamirins e pitangueira) e Anacardiaceae (aroeiras). Na região metropolitana de Porto Alegre, em levantamentos realizados (Baptista \& Irgang, 1972), foram constatadas, em uma amostra, a presença de 85 espécies florestais, com predominância de espécies e indivíduos da família Myrtaceae. No Vale do Jacuí, próximo a Cachoeira do Sul, foram encontradas 81 espécies (Schultz, 1957). A análise desta lista de 81 espécies nos mostra a presença de representantes do Alto Uruguai misturados às espécies da Depressão Central e ainda a presença de pinheiro (Araucaria angustifolia).

Sobre a Serra do Sudeste, até o encontro dos campos da campanha existe uma vegetação florestal esparsa de pequeno porte e até raquítica e retorcida, sobre os afloramentos de rocha, com predominância de aroeiras (família Anacardiaceae) e branquiIho (Sebastiania spp.). Também encontramos em toda a região o pinheiro-bravo (Podocarpus lambertii).

Mais ao oeste, na região de São Borja, encontramos manchas quase homogênas de pau-ferro (Astronium balansae), uma vegetação chaquenha já bastante depredada pela exploração da madeira.

Em toda a região da Depressão Central e Serra do Sudeste não existem parques ou reservas dignas deste nome. A Prefeitura de Porto Alegre mantém duas pequenas áreas reservadas (Lamie St. Hilaire). O governo estadual criou, por decreto, alguns parques nesta, e em outras regiões do Estado, que jamais foram desapropriadas e implantadas.

As matas da Depressão Central são bastante depredadas e em vias de desaparecimento devido à agricultura de rapina e à expansão dos centros urbanos. A interessante vegetação da Serra do Sudeste está ameaçada pela mineração. Atualmente estas matas, e principalmente as próximas a cidades, es- 
tão sendo muito devastadas pela procura de lenha para substituir o gás de fogões, inacessível à população pobre devido à crise do petróleo.

\section{Monoculturas florestais}

Partindo da idéia de que os chamados florestamentos ou reflorestamentos em sistema de monocultura são uma prática agrícola, pela implantação de verdadeiras lavouras de madeira, e como tal devem ser tratados, ainda não temos uma verdadeira política de regeneração e conservação das matas nativas. É perfeitamente válido o cultivo de árvores exóticas neste conceito de prática agrícola com finalidades extrativas. Pode-se, entretanto, criticar esta prática por ser feita em monocultura e sobre solos nobres, com todas as péssimas conseqüências daí resultantes. Os reflorestamentos deveriam obedecer necessariamente a ocupação do solo segundo sua classificação de uso. Pode-se, também, defender o uso de espécies nativas para esta finalidade.

Cultiva-se, principalmente, espécies de eucalipto (Eucalyptus spp.), para lenha e celulose; acácianegra (Acacia mearnsii), para extração de tanino e lenha; e diversos pinheiros (Pinus spp.), para celulose e indústria química. Também muito usada, no litoral, é a casuarina (Casuarina equisetifolia) com finalidades de arborização e quebra-ventos. Os cultivos de acácia-negra, pinus e eucalipto, até o final de 1982, cobriam uma área de 339.919 hectares (IBGE, 1982).

Do ponto de vista conservacionista, é mais danoso ao ecossistema o cultivo das diferentes espécies de Pinus, principalmente pelas alterações edáficas que causam. De maneira geral, todas as exóticas introduzidas produzem algum tipo de dano ambiental, especialmente quanto à fauna. Lamentável é o fato de não se conhecer bem, nem se estudar meIhor estas conseqüências sobre o ecossistema natural.

Outro aspecto importante a considerar é a adulteração da paisagem do Estado do Rio Grande do Sul. Primitivamente coberto com uma mata heterogênea, rica em vida, hoje certas regiões mais se parecem paisagens européias ou australianas.

O planejamento da vegetação deve ser feito a nível de propriedades, com uma zonação ecológica, a partir da qualidade dos solos, em áreas de cultivos permanentes, anuais, quebra-ventos, matas para corte e áreas de preservação permanente.

\section{Conclusões}

Os remanescentes das matas originais são cada vez mais raros e estão realmente em péssimo estado, excetuando-se as pequenas e poucas reservas florestais que, por sua vez, estão ameaçadas por outros fatores, tais como, barragens, disputas judiciais e invasões. Estas reservas devem ser mantidas e preservadas, como determina a lei, e seu número deve ser urgentemente aumentado, abrangendo todos os tipos de vegetação e fauna existentes.

Creio que reservas criadas e mantidas por particulares têm maior possibilidade de sobrevivência que as reservas públicas, estas sempre sujeitas às flutuações políticas que ocorrem periodicamente, como também sujeitas a freqüentes mudanças de opinião dos "técnicos".

Devemos distinguir, perfeitamente, a finalidade agrícola das monoculturas florestais de florestas de preservação.

A maneira mais simples, mais barata e mais lógica de se restaurar, regenerar ou reflorestar com espécies nativas é, simplesmente, abandonar e não interferir nas áreas para isto previstas, a fim de que a natureza se encarregue do processo.

As conseqüências da devastação florestal, previstas há muito tempo pelos botânicos e pelos ecólogos, hoje já são bastante visíveis como o declínio da produção agrícola pela erosão do solo, aumento de pragas, e as enchentes cada vez mais violentas que assolam a Região Sul do Brasil.

\section{Referências bibliográficas}

BAPTISTA, L.R.M. \& IRGANG, B.E. Nota sobre a composição florística de uma comunidade florestal dos arredores de Porto Alegre. Porto Alegre, Iheringlia, 16:3-8, 1972.

BETTIOL, A.I. \& MASLAK, M.I.G. Programa de reflorestamento estadual, 1974-1983. Porto Alegre, SRNR/S. Agricultura, Porto Alegre, 1973.

HUECK, K. \&SEIBERT, P. Vegetationskarte von Südamerika. Stuttgart, G. Fischer Verlag, 1972

IBGE. Rio de Janeiro. Silvicultura, 1982.

LINDMAN, C.A.M. A vegetação no Rio Grande do Sul. Porto Alegre. Livraria Universal, 1906.

RAMBO, B. A fisionomia do Rio Grande do Sul. Porto Alegre. Livraria Sefbach, 1956.

Regenwald und Rio Grande do Sul. Itajai. Sellowia, 8,: 256-298, 1957

SAINT-HILAIRE. A. Viagem ao Rio Grande do Sul (1820-1821). São Paulo, USP, 1974.

SCHULTZ, A: R. Some fitogeografical and fitological data from Rio Grande do Sul. Den Haag, Vegetatio Acta Botanica, $7(5 / 6):$ 355-360, 1957.

SUDESUL. Vegetação atual da Região Sul. Porto Alegre, 1978.

FERREIRA, L.A.B. Áreas de preservação no Rio Grande do Sul, estado atual e perspectivas. In: ANAIS DO I SIMPOSIO NACIONAL DE ECOLOGIA, 5. Curitiba, 1978 


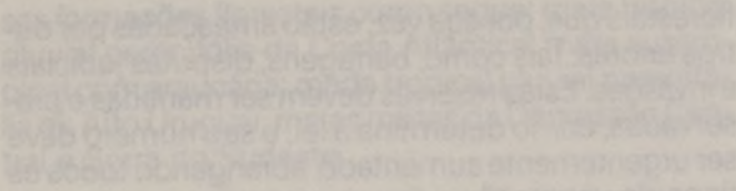

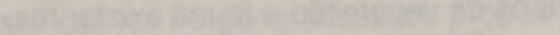

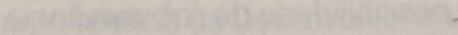

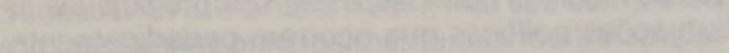

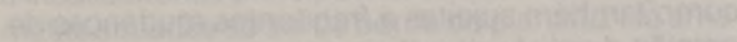

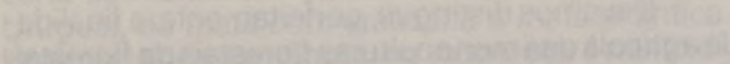

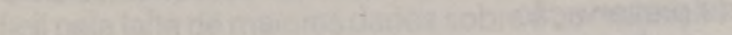

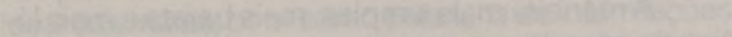

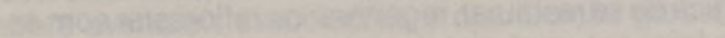

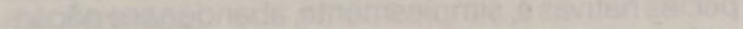

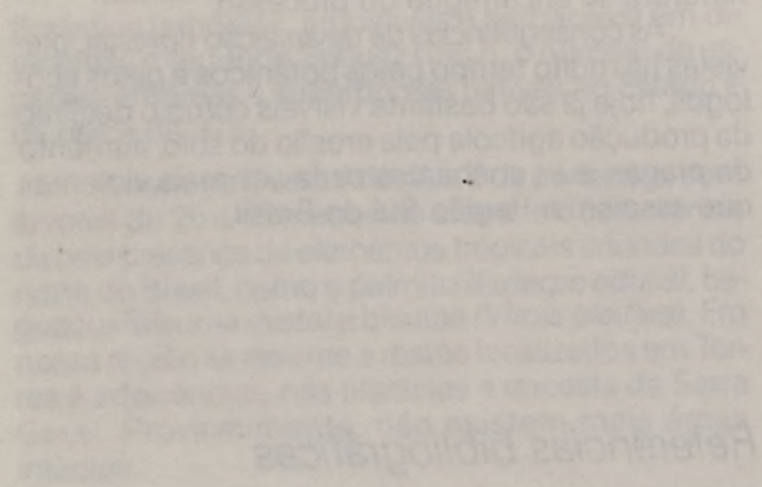

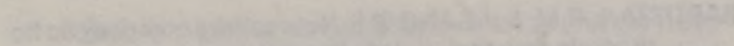

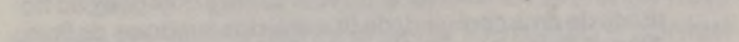

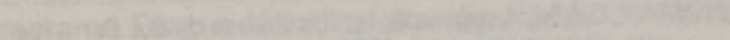

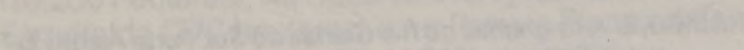

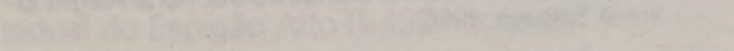

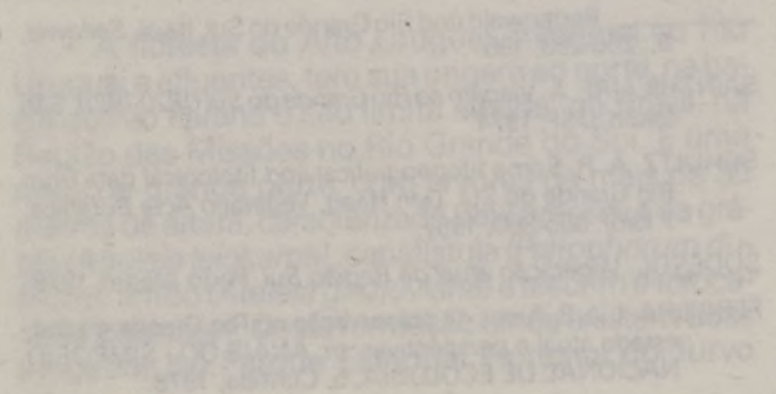

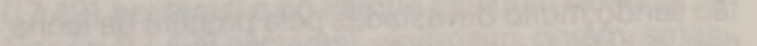

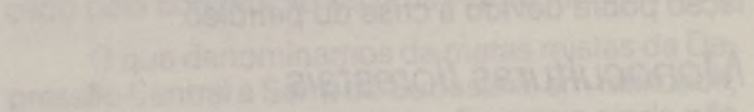

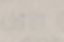

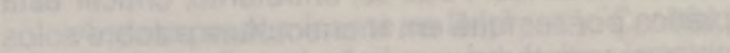

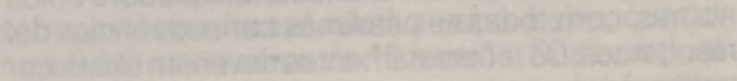

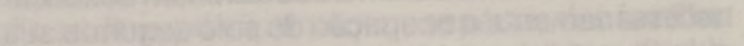

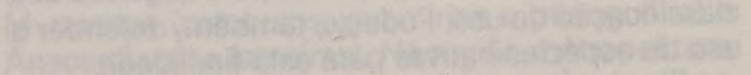

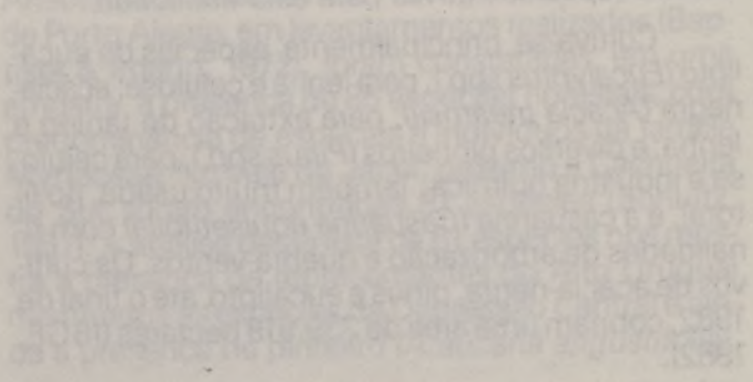

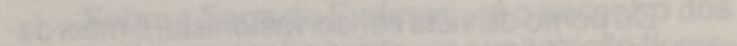

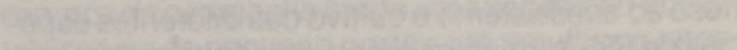

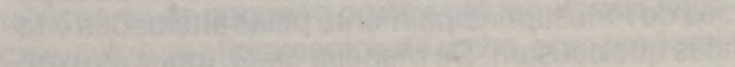

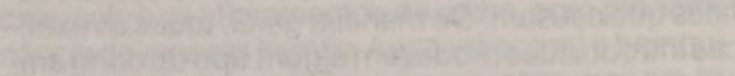

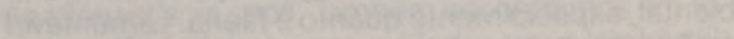

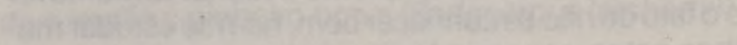

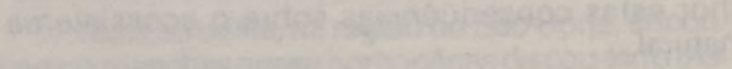

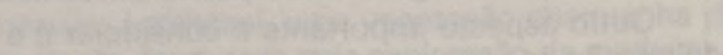

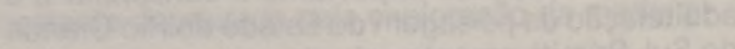

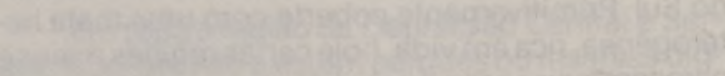

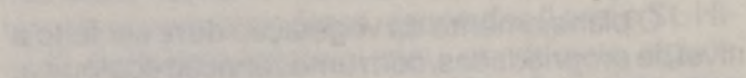

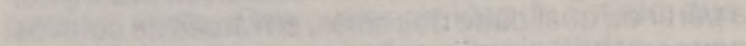

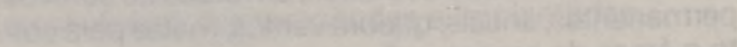

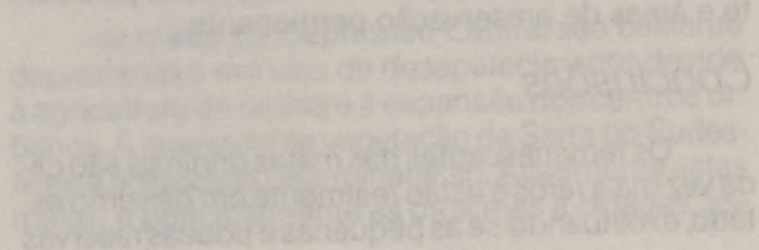

